\title{
Interrelationship of Physical Fitness of Female College Students with Hidden Obesity
}

\author{
Takanobu OKAмото ${ }^{1}$; Mitsuhiko MaSUHARA ${ }^{2}$; and Komei IKUTA ${ }^{3}$ \\ ${ }^{1}$ Faculty of Social Welfare, Kinki Welfare University, ${ }^{2}$ Laboratory of Exercise Physiology and Biochemistry, Osaka University of Health and Sport \\ Sciences, and ${ }^{3}$ School of Health and Sport Sciences, Osaka University
}

\begin{abstract}
Objective The purposes of this study were to measure the muscle strength, muscle power, aerobic ability and muscle endurance of people with hidden obesity for comparison with those of a control group, to clarify the relation between muscle strength, muscle power, aerobic ability and muscle endurance, and to examine the interrelationship of the physical fitness of female college students with hidden obesity.

Metbods Subjects were 178 healthy adult women. We measured the height, weight, body fat, body mass index (BMI) and waist/hip ratios of the subjects and classified them into a control group ( 83 person), hidden obesity group (40 person), obesity group ( 30 person) and slender group ( 25 person). The subjects of the control group and hidden obesity group had grip strength, vertical jump, step test and upper body raising, in order to measure their muscle strength, muscle power, aerobic ability and muscle endurance. Since significant differences were recognized in the weight, body fat and BMI of the control group and the hidden obesity group, based on the preceding study, 15 subjects who do not have differences in weight, body fat and BMI were extracted at random from each group and their physical fitness indicators were compared.
\end{abstract}

Result and Discussion Significant differences were recognized in items except the decision index for the step test. In the control group, a significant correlation was recognized between items except grip strength and upper body raising. On the other hand, in the hidden obesity group, a significant correlation was not recognized between items. The athletic histories of the hidden obesity group showed low values significantly compared with those of the control group.

Conclusion It was thought that the diminished physical fitness of subjects with hidden obesity was caused by the fact that insufficient physical activities from school age until now suppressed the development of lean body mass, especially muscle mass, and deteriorated muscle functions. Moreover, it was suggested that synthetic physical fitness has not been developed harmoniously in subjects with hidden obesity.

Key Words Female College Student, Hidden Obesity, Physical Fitness

Received: May 7, 2004

${ }^{1}$ Address; Faculty of Social Welfare, Kinki Welfare University, 1966-5, Takaoka, Fukusaki-cho, Kanzaki-gun, Hyogo, 679-2217 Japan. TEL: 81-790-22-2620, FAX: 81-790-23-0662, E-mail:

\footnotetext{
${ }^{2}$ Address; Laboratory of Exercise Physiology and Biochemistry, Osaka University of Health and Sport Sciences, 1-1, Asashirodai, kumatori, Sennan, Osaka, 590-0496 Japan. TEL: 81-724-53-8844, FAX: 81-724-53-8844, E-mail:

${ }^{3}$ Address; School of Health and Sport Sciences, Osaka University, 1-5, Machikaneyama, Toyonaka, Osaka, 560-0043 Japan. TEL: 81-6-6850-6033, FAX: 81-6-6850-6030, E-mail:
}

\section{INTRODUCTION}

Recently, young women (high school students and college students) are inclining toward lean figure ${ }^{[1]}$ and it is thought that this inclination promotes the reduction of lean body mass through wrong diets. ${ }^{[2]}$ Most of the typical wrong diets are based only on food restriction, and it has been shown clearly that this process causes the fall of insulin-like growth factor-1 (IGF-I) and induces the reduction of muscle mass and bone mass. ${ }^{[3]}$ That is, diets only by food restriction decrease lean body mass greatly ${ }^{[4],[5]}$ and may cause hidden obesity, though the effect of weight loss itself is recognized.

Ruderman et al. ${ }^{[6]}$ published the paper titled The "metabolically-obese" normal-weight individual in 1981, and mentioned insufficient physical activities, insulin resistance and an advanced age as the three characteristics of obese persons with normal weight. However, in recent years, hidden obesity is found among both men and women in their late twenties, ${ }^{[7]}$ and it is known that hidden obesity exists among younger women (high school students and college students). ${ }^{[2]}$ Furthermore, Fujise et al. ${ }^{[7]}$ reported that about 30\% of ordinary female students are suffering or expected to suffer from hidden obesity.

Many studies have been conducted so far on the characteristics of the physical fitness of obese persons. The reports of those studies say that obese persons have higher static strength $^{[8]}$ but are inferior in physical fitness accompanying weight shifts (vertical jump power etc.) ${ }^{[9]}$ compared with nonobese persons. On the other hand, concerning the characteristics of the physical fitness of people with hidden obesity, it is reported that they have lower physical fitness than obese and non-obese persons and that especially the fall of muscular power is remarkable. ${ }^{[10]}$ However, the characteristics of the physical fitness of people with hidden obesity have not been clarified sufficiently, and the interrelationship of the characteristics of physical fitness has not been investigated.

Therefore, the purposes of this study were to measure the aerobic ability and muscle endurance of people with hidden obesity for comparison with those of a control group, to clarify the relation between aerobic ability and muscle endurance, and to examine the interrelationship of the physical fitness of female college students with hidden obesity. 


\section{METHODS}

\section{Subjects}

Subjects were 178 healthy adult women (18-19 years old). To the subjects, the gist of the experiment and objectives was orally and with printed materials explained, and then written consents were obtained prior to the start of the experiment.

\section{Determination of body size}

We determined height, weight, body mass index (BMI), body fat, lean body mass and waist/hip ratio for the determination of body size in this study. The height was determined with use of metal height measure (Yagami, Inc.). The weight, BMI, body fat and lean body mass were determined with use of weight-body fat balance (BF-580, Tanita, Inc.). We figured out the waist/hip ratio by measuring maximum circumferences of the waist and of the hip part by a measure and dividing the maximum circumference of the waist by that of the hip.

\section{Classification of the subjects}

According to the results of the measurement of body size and body fat, those given standard BMI (18.5-25) and with body fat less than $30 \%$ are classified into control group; those given standard BMI (18.5-25) and with body fat over $30 \%$ into hidden obesity group; those given obesity BMI (over 25) into the obesity group; those given lean BMI (under 18.5) into the lean group. The breakdown is the control group 83 person; the hidden obesity group 40 person; the obesity group 30 person; and the lean group 25 person. The classification of each group is based on the BMI sheet of the Japan Society for the Study of Obesity revised in 2000. In addition, the hidden obesity group was only compared with the control group, and not with the obesity group or the lean group in order to clarify the hidden obesity persons' characteristics of physical fitness in this study.

\section{Determination of physical fitness}

We determined grip strength as the determination of muscle strength, had a vertical jump as that of muscle power, had a step test as that of the aerobic ability, and had them upper body raising as that of the muscle endurance.

1) Determination of grip strength: we used a digital grip strength meter (Takei, Inc.) to determination grip strength. A subject, straightly standing, holds a digital grip strength meter with the maximum effort, making a right angle at the second joint of the index finger. The measurement was done twice, from which the larger value was recorded.

2) Determination of vertical jump: we used a digital vertical jump meter (Takei, Inc.) to measure vertical jump. A subject, straightly standing, attaches a belt with a digital vertical jump meter on the waist measured the jump with the maximum effort. The determination was done twice, from which the larger value was recorded.

3) Determination of the aerobic ability: aerobic ability was determined by the step test (bench stepping test) comprising stepping up and down on the steps at a rate of 30 times per minute for consecutive 3 minutes; subsequently, every $30 \mathrm{sec}$ onds heart rates were determined 1,2 and 3 minutes after completion of the step test. Incidentally, the height of the step was fixed at $35 \mathrm{~cm}$ from the floor. The decision index was calculated from the obtained heart rates $((180 \times 100) /$ $(2 \times($ Total of the triplicate heart rates $)))$.

4) Measurement of the muscle endurance: for determination of trunk muscle endurance, abdominal muscle exercises consisting of repetition of upper-body raising exercises for 30 seconds under the maximum efforts were performed. Prior to determination of the abdominal muscle exercises by means of the upper-body raising exercises, a couple of subjects formed each pair; one partner as the subject took a supine position with both legs opened to place them $30 \mathrm{~cm}$ apart and bent knees at right angle, with both hands piled up under the head while another partner firmly fixed both ankles of the subject. Immediately after a certain signal, the subject commenced upper body raising exercises. The upper body was firmly raised until both elbows reached both knees, followed by lowering the upper body until the back reached the floor; these movements were repeated for 30 seconds.

\section{Statistical analysis}

All the data obtained in the present study were presented by mean $\pm \mathrm{SD}$. The paired $t$-test was used for testing the control group and the hidden obesity group. For analysis of the correlation efficient, Pearson's correlation efficient assay method was used. Incidentally, the data were considered significant if $\mathrm{P}$ was less than $5 \%$.

\section{RESULTS}

Comparison of physical characteristics in the control group and the hidden obesity group.

Table 1 illustrates physical characteristics in the control group and the hidden obesity group weight, body fat, and BMI of the hidden obesity group were significantly higher than control group.

Comparison of physical exercise histories in the control

Table 1 Physical characteristics of control and hidden obesity group.

\begin{tabular}{c|c|c|c}
\hline & $\begin{array}{c}\text { control group } \\
(n=83)\end{array}$ & $\begin{array}{c}\text { hidden obesity } \\
\text { group }(n=40)\end{array}$ & significant \\
\hline height $(\mathrm{cm})$ & $157.7 \pm 5.6$ & $157.1 \pm 5.8$ & N.S \\
\hline weight $(\mathrm{kg})$ & $50.8 \pm 4.9$ & $56.2 \pm 5.4$ & $p<0.001$ \\
\hline BMI & $20.4 \pm 1.2$ & $22.8 \pm 1.2$ & $p<0.001$ \\
\hline body fat $(\%)$ & $25.3 \pm 3.1$ & $33.5 \pm 2.8$ & $p<0.001$ \\
\hline lean body mass $(\mathrm{kg})$ & $37.8 \pm 3.1$ & $37.4 \pm 3.5$ & N.S \\
\hline W/H ratio & $0.77 \pm 0.09$ & $0.79 \pm 0.1$ & N.S \\
\hline
\end{tabular}

Table 2 Comparison of exercise hastory of control and hidden obesity group.

\begin{tabular}{c|c|c|c}
\hline & $\begin{array}{c}\text { control group } \\
(n=83)\end{array}$ & $\begin{array}{c}\text { hidden obesity } \\
\text { group }(n=40)\end{array}$ & significant \\
\hline $\begin{array}{c}\text { exercise } \\
\text { history (years) }\end{array}$ & $5.1 \pm 3.7$ & $3.4 \pm 2.5$ & $p<0.05$ \\
\hline
\end{tabular}


group and the hidden obesity group.

Table 2 demonstrates physical exercise histories in the control group and the hidden obesity group. A physical exercise history is defined as the total number of years in which physical exercises were regularly done in elementary, junior high, and senior high schools. Physical exercise histories in the hidden obesity group were significantly lower than control group.

Comparison of grip strength, decision index of step test, vertical jump, and upper-body raising in the control group and the hidden obesity group.

Table 3 shows grip strength, decision index of step test, vertical jump, and upper-body raising in the control group and the hidden obesity group. The values were significantly high in the hidden obesity group compared with control group as for weight, body fat, and BMI in Table 1. Therefore, it is possible that hidden obesity persons' physical character-

Tabel 3 Comparison of grip strength, vertical jump, decision index and upper body raising in the control and hidden obesity group.

\begin{tabular}{c|c|c|c}
\hline & $\begin{array}{c}\text { control group } \\
(n=15)\end{array}$ & $\begin{array}{c}\text { hidden obesity } \\
\text { group }(n=15)\end{array}$ & significant \\
\hline $\begin{array}{c}\text { grip strength } \\
(\mathrm{kg})\end{array}$ & $25.1 \pm 3.9$ & $22.2 \pm 3.6$ & $p<0.05$ \\
\hline $\begin{array}{c}\text { vertical jump } \\
(\mathrm{cm})\end{array}$ & $38.5 \pm 5.6$ & $34.5 \pm 4.6$ & $p<0.05$ \\
\hline $\begin{array}{c}\text { decision index } \\
\text { upper body } \\
\text { raising (times) }\end{array}$ & $63.9 \pm 8.0$ & $60.7 \pm 18.4$ & $\mathrm{~N} . \mathrm{S}$ \\
\hline
\end{tabular}

istics may not be clarified even if physical characteristic measurement is achieved with these subjects. A comparison and contrast was also done between a control group and a hidden obesity group where there was no meaning difference in terms of height and weight in the previous study report. ${ }^{[2],[11]}$ In this study, thus, we randomly selected 15 subjects of each group who do not show any significant difference in height and weight examining them in comparison and contrast. There were significant differences in grip strength, vertical jump, and upper-body raising between the control group and hidden obesity group, while there were no significant differences detected in the decision index of step test.

Relationship between muscle strength, muscle power, aerobic ability and muscle endurance in the control group and the hidden obesity group.

Table 4 illustrates relationship between muscle strength, muscle power, aerobic ability and muscle endurance in the control group and the hidden obesity group. Significant correlation was observed between any two items except grip strength and upper-body raising in the control group. In contrast, no significant correlation was found between the muscle strength, muscle power, aerobic ability and muscle endurance in the hidden obesity group.

\section{DISCUSSION}

Some decrease of lean fat tissue is observed in the "normal weight obesity" or the so-called "hidden obesity," which is different from obesity with overweight. The decrease of lean body tissue due to decrease of the physical activity ${ }^{[2]}$ can be given as a main reason for that. Furthermore, it has been

Table 4 Correlation coefficient between grip strength, vertical jump, decision index and upper body raising in the control and hidden obesity group.

\begin{tabular}{|c|c|c|c|c|}
\hline $\begin{array}{l}\text { control group } \\
\quad(n=15)\end{array}$ & $\begin{array}{c}\text { grip strength } \\
(\mathrm{kg})\end{array}$ & $\begin{array}{l}\text { vertical jump } \\
(\mathrm{cm})\end{array}$ & decision index & $\begin{array}{l}\text { upper body } \\
\text { raising (times) }\end{array}$ \\
\hline $\begin{array}{l}\text { grip strength } \\
(\mathrm{kg})\end{array}$ & & $p<0.01$ & $p<0.05$ & N.S \\
\hline $\begin{array}{l}\text { vertical jump } \\
\quad(\mathrm{cm})\end{array}$ & 0.712 & & $p<0.05$ & $p<0.05$ \\
\hline decision index & 0.553 & 0.552 & & $p<0.05$ \\
\hline $\begin{array}{l}\text { upper body } \\
\text { raising (times) }\end{array}$ & 0.508 & 0.554 & 0.602 & \\
\hline $\begin{array}{l}\text { hidden obesity } \\
\text { group }(n=15)\end{array}$ & $\begin{array}{l}\text { grip strength } \\
(\mathrm{kg})\end{array}$ & $\begin{array}{l}\text { vertical jump } \\
(\mathrm{cm})\end{array}$ & decision index & $\begin{array}{l}\text { upper body } \\
\text { raising (times) }\end{array}$ \\
\hline $\begin{array}{l}\text { grip strength } \\
(\mathrm{kg})\end{array}$ & & N.S & N.S & N.S \\
\hline $\begin{array}{l}\text { vertical jump } \\
(\mathrm{cm})\end{array}$ & 0.077 & & N.S & N.S \\
\hline decision index & -0.107 & 0.014 & & N.S \\
\hline $\begin{array}{l}\text { upper body } \\
\text { raising (times) }\end{array}$ & 0.233 & -0.158 & 0.413 & \\
\hline
\end{tabular}


thought that wrong diet methods have contributed to the increase of the breakouts of hidden obesity cases in the turmoil of diet booms these years. ${ }^{[1]}$ By examining the lean body mass of hidden obesity persons with the 278 subjects of female junior college students, Nakata et al. ${ }^{[10]}$ have reported that there were significantly low values observed in the comparison and contrast with the control and obesity group. In this study, however, there was significant difference in body fat and BMI detected in the comparison and contrast between control and hidden obesity groups. According to this result, it can be thought that hidden obesity persons, even within the range of normal weight, have stronger inclination toward obesity in comparison to controls. It is natural, thereby, that there is a significant difference detected in body fat and BMI of both groups. However, the reality of hidden obesity persons cannot be clarified in comparing and contrasting both groups' physical characteristics when there is significant difference detected in body fat and BMI. A previous study also compared and contrasted a control group with a hidden obesity group with no significant difference in height and weight. ${ }^{[2],[11]}$ Accordingly, this study also examined in a comparative manner a control and a hidden obesity group without any significant difference. Eventually, there were significant differences identified in grip strength, vertical jump, and upper-body raising with an exception of decision index of step test. A previous study measured grip strength, back muscle strength, vertical jump, and upper-body raising among others, in each of which items it is reported that a hidden obesity group showed significantly low values compared to controls. ${ }^{[10]}$ As is stated above, the decrease of lean fat tissues can be given as a characteristic of hidden obesity persons. Tsuji et al. ${ }^{[3]}$ have identified short physical exercise history and decrease in the physical activities as main causes for the decrease of hidden obesity persons' lean body tissues. Kajioka et al. ${ }^{[2]}$ also have reported that hidden obesity persons have less physical exercise experience since school ages and that the their physical activities in daily lives showed significantly low values compared with control group. This study also shows that the total number of years of hidden obesity persons' physical exercise history during elementary, junior high school and high school years is a significantly low value compared with that of control group. In other words, it can be considered that hidden obesity persons have less physical exercise experiences since school ages not causing the increase of lean body tissues, especially of the skeletal muscles. A previous study has confirmed that there is a significant correlation between the amount of lean body mass and muscle strength. ${ }^{[12]}$ These studies indicate that it could be thought that the physical fitness of hidden obesity persons is a result of the underdeveloped muscle strength and the decrease of muscle functions due to a lack in the physical activities from school ages to the present.

A previous study has reported that obesity persons are inferior to non-obesities in physical fitness and physical exercise ability in moving bodies. ${ }^{[13]}$ Nakata et al. ${ }^{[10]}$ and Fujise et al. ${ }^{[11]}$ have also reported about hidden obesity persons in a manner similar to obesities. However, there had been no study done on the muscle strength, muscle power, aerobic ability and muscle endurance; therefore, we tried to study the correlations of grip strength, vertical jump, step test and upper-body raising, which serve as indexes for each. Eventually, there have been significant correlations found in control group every item with the exceptions of vertical jump and upper-body raising, while there have been no significant correlations detected between each items in the hidden obesity group. That is, it seems that there is a cooperation working between the muscle strength, muscle power, aerobic ability and muscle endurance in control group. On the other hand, it is suggested that there is little cooperation between the muscle strength, muscle power, aerobic ability and muscle endurance in the hidden obesity group and that their synthetic physical fitness (muscle strength, speed and endurance ${ }^{[14]}$ ) is scarce. Shite et al. ${ }^{[15]}$ have studied the relationship between shortdistance running, which requires muscle strength and muscle prowess, and long-distance running, which requires the aerobic ability and that of muscle endurance, with the subjects of elementary school children in their senior years and have reported that there was a significant correlation between them. In other words, it is thought that while the three elements of muscle strength, speed, and endurance ${ }^{[14]}$ grow side by side in control group, the hidden obesity group, which their little physical exercise experiences since their school years, have grown up with their development in immaturity.

As for potential obesity, its relationship to lifestyle-related diseases has also been put into questions in addition to the decrease of muscle strength due to the decrease of lean body mass. ${ }^{[3]}$ Ruderman et al. ${ }^{[16]}$ have also reported that a reduced skeletal muscles could be a dangerous factor of diabetes and heart diseases related to hardened arteries by aggravating glucose metabolism and bringing about insulin resistance. It seems that a more detailed study will be needed as to physical fitness of hidden obesity persons from now on.

It was thought that the diminished physical fitness of subjects with hidden obesity was caused by the fact that insufficient physical activities from school age until now suppressed the development of lean body mass, especially skeletal muscle, and deteriorated muscle functions. Moreover, it was suggested that synthetic physical fitness (muscle strength, speed and endurance) has not been developed harmoniously in subjects with hidden obesity.

\section{CONCLUSION}

We investigated the relation between muscle strength, muscle power, aerobic ability and muscle endurance, and to examine the interrelationship of the physical fitness of female college students with hidden obesity. Physical fitness and physical exercise histories in hidden obesity were significantly lower than control group. Moreover, no significant correlation was found between the muscle strength, muscle power, aerobic ability and muscle endurance in the hidden obesity group. It was suggested that synthetic physical fitness (muscle 
strength, speed and endurance) has not been developed harmoniously in subjects with hidden obesity.

\section{REFERENCES}

[1] Takeuchi S: Change of the Body and Female High School Student. Science of the Mind 56: 28-32, 1994

[2] Kajioka T, Osawa I, Yoshida T, Sato Y: Body and Lifestyle Characteristics in Normal Weight Obesity (Masked Obesity) in Japanese Female High School Students. Jap J School Health 38: 263-269, 1996

[3] Tsuji H, Katsukawa F, Ohnishi S, Yamazaki H: Masked Obesity and Osteoporosis. - Against the Background of Physical Activity-. Osteoporosis Japan 4: 59-65, 1996

[4] Zuti WB, Golding LA: Comparing Diet and Exercise as Weight Reduction Tools. Physician Sportsmed 4: 49-53, 1976

[5] Wood PD, Stefanick ML, Dreon DM, et al.: Changes in Plasma Lipids and Lipoproteins in Overweight Men During Weight Loss Through Dieting as Compared with Exercise. N Engl J Med 319: 1173-1179, 1988

[6] Ruderman NB, Schneider SH, Berchtold P: The "Metabolically-obese," Normal-weight Individual. Am J Clin Nutr 34: 1617-1621, 1981

[7] Katsukawa F, Tsuji H, Ohnishi S, Yamazaki H: Importance of Body Fat Measurement. - Validity of Near Infrared Spectroscopy Method and Characteristics of Masked Obesity-. The 14th Japan Society for the Study of Obesity record, 84-
86,1993

[8] Beunen G, Malina RM, Ostyn M, Renson R, Simons J, Van GD: Fatness, Growth and Motor Fitness of Belgian Boys 12 Through 20 Years of Age. Hum Biol 55: 599-613, 1983

[9] Hayashi S: Examination About Physical Fitness and Motor Ability in Obese Students. Japanese Journal of School Health 30: 30-37, 1988

[10] Nakata H, Mima S, Okazaki N, Goto E, Otsuki S, Mimura K: Physical Fitness of Normal Weight Obesity in Female Junior College Students. Osaka R J Phys Educ 37: 30-37, 1999

[11] Fujise T, Nagasaki K: Characteristics of Anthropometry and Physical Fitness of Masked Obesity in Young Men and Women. Jap J Phys Fitness Sports Med 48: 631-640, 1999

[12] Kitagawa K, Miyashita M: Muscle Strengths in Relation to Fat Storage Rate in Young Men. Eur J Appl Physiol Occup Physiol 38: 189-196, 1978

[13] Kim HK, Matsuura Y, Tanaka K, Inagaki A: Physical Fitness and Motor Ability in Obese Girls Aged 12 to 14years. Jap J Phys Fitness Sports Med 42: 380-388, 1993

[14] Ikai M: Physical Fitness Studies in Japan. Res J Physical Educ 6: 1-14, 1962.

[15] Shite N, Sasaki K, Shimada S, Shinkaiya H: The Relationship between Sprint and Endurance Running Performances in 5th and 6th Graders. J Hokkaido Univ Education 45: 168175,1995

[16] Ruderman NB, Schneider SH: Diabetes, Exercise, and Atherosclerosis. Diabetes Care 15: 1787-1793, 1992 